\title{
HOSPITAL BASED STUDY FOR ASYMPTOMATIC BACTERIURIA IN PREGNANT WOMEN
}

Babita1 ${ }^{1}$ Sanjeev Suman², Shankar Prakash ${ }^{3}$

\section{HOW TO CITE THIS ARTICLE:}

Babita, Sanjeev Suman, Shankar Prakash. "Hospital based study for asymptomatic bacteriuria in pregnant women". Journal of Evolution of Medical and Dental Sciences 2013; Vol. 2, Issue 44, November 04; Page: 8574-8577.

BACKGROUND: Asymptomatic bacteriuria (ASB) is infection in pregnancy which requires medical treatment. If left untreated, may lead to prematurity, intrauterine death and pyelonephritis. The diagnosis is done by culture and its antibiotic sensitivity helped the women in treatment. AIMS \& OBJECTIVE: The study was done to determine the asymptomatic bacteriuria during pregnancy by culture and also its antibiotic sensitivity. METHODS \& MATERIALS: This study was done on 196 pregnant women. The specimens ware analyzed by pyuria, catalase test, nitrate reduction test, culture and sensitivity test. RESULTS: Out of 196 pregnant women, 22 showed positive culture growth and culture was the effective method in screening. The prevalence of asymptomatic bacteriuria increased with age. Escherichia coli was the commonest organism isolated. The isolated organisms showed increased sensitivity to amikacin and lowest sensitivity to ampicillin. CONCLUSION: Asymptomatic bacteriuria is a common problem in pregnant women which requires diagnosis and treatment. The diagnosis may lead to reduction of the adverse effect in pregnancy.

INTRODUCTION: Urinary tract infection (UTI) affects women particularly pregnant women more than men due to short urethra, pregnancy, easy contamination of urinary tract with fecal flora. [1] Profound physiological and anatomic changes in the urinary tract during pregnancy contribute to the increased risk for infection. Asymptomatic bacteriuria (ASB) is defined as pure cultures of at least $10^{5}$ organisms/ml of urine in the absence of symptoms. [2] Asymptomatic bacteriuria may lead to acute pyelonephritis, postpartum UTI, hypertensive disease, anemia, prematurity and low birth weight babies if left untreated in pregnant women. A prevalence of 2-10 percent has been reported. [3][4] Escherichia coli is the most common organism associated with bacteriuria. ${ }^{[5]}$ Specific virulence factors in uropathogenic strains of E.coli may be helpful for adherence to uroepithelial cells tissue invasion such as toxins and adhesins, pili or fimbriae. [6]

Urine culture is the gold standard screening technique for asymptomatic bacteriuria during pregnancy. ${ }^{[7]}$ Therefore, if routine screening for asymptomatic bacteriuria and its treatment is done, the development of chronic renal disease in pregnant women and fetal loss due to complication of urinary tract infections may be reduced. [8] The present study was done to determine the prevalence of asymptomatic bacteriuria among pregnant women attending out patient department.

MATERIAL AND METHOD: This study was conducted in Microbiology department during 1st May 2011 to 30 April 2012. 196 women in their first, second or third trimesters of pregnancy were included for the study. Cases from outpatients enrolled for the study. Pregnant woman with history of fever with chills, genito urinary complaints, pregnancy induced hypertension and also patients on antibiotic treatment during the pregnancy were excluded. Pregnant women were enrolled on the basis of age group 15-25 and 26-40 years, for the study. Asymptomatic pregnant women were 
divided by their gestational age Group A - 1-12 weeks, Group B - 13 -24 weeks, Group C- 25-30 weeks.

A clean-catch mid stream urine sample was collected in a sterile container. Culture vials so collected were sent to laboratory for microscopy, catalase test, nitrate reduction test, culture and sensitivity, within half to one hour. The specimens were analyzed by the following methods.

1. Detection of pyuria - The number of leucocytes /ml were measured in uncentrifuged urine using haemocytometer. The leucocytes were counted in squares present at the four corners of the counting chamber.

2. Catalase test - Frothing was observed on addition of few drops of Hydrogen peroxide to $1 \mathrm{ml}$ sample of urine. The positive reaction was due to catalase enzyme.

3. Nitrate reduction test - Pink red color appeared which indicate the pres ence of nitrite.

4. Culture and sensitivity testing - This was done by semi quantitative calibrated loop method. The urine was mixed thoroughly and inoculated on cysteine lactose electrolyte deficient media (CLED) and its sensitivity was done.

It was the incubated overnight at $35-37^{\circ} \mathrm{C}$ in air and then colonies were counted. Counts $>10^{5}$ organisms/ml were considered as significant bacteriuria. Insignificant growth was reported if colony count were less the $10^{5} \mathrm{CFU}$ per ml of urine except in case of growth of Staphylococcus aureus where even $10^{2} \mathrm{CFU}$ per $\mathrm{ml}$ were taken as significant. The isolates were tested for sensitivity using drugs safe in pregnancy namely amoxicillin, cefuroxime, cefotaxim, amikacin, ampicillin and nitrofurantion. The organisms were isolated and species were identified. Antibiotic sensitivity was tested for the isolated organism by Kirby - Bauer method (disk diffusion) with 0.5 McFarland Standard turbidity of the inoculums on Mueller-Hinton agar.

RESULTS: Out of 196 cases, asymptomatic pregnant women with positive culture were 22(11.2\%) Among the positive culture $16(9.7 \%)$ cases were between the ages $15-25$ years and $6(19.3 \%)$ cases were between the ages of 26 -35 years. 165 (84.2\%) cases belonged to 15-25 age group and 31 (15.8\%) case belonged to 26-40 age group. 30 women which were enrolled in 1 - 12 weeks of gestation showed $5(16.6 \%)$ positive culture. Out of 135 cases between $13-24$ weeks of gestation, 11 (8.1\%) showed positive cultures and among 31 cases in 25- 32 weeks of gestation 7 (22.5\%) showed positive cultures.

\begin{tabular}{|c|l|c|c|}
\hline Serial No. & Culture Isolates & Women with Significant Bacteriuria & Percentage \\
\hline 1. & Escherichia Coli & 9 & $40.90 \%$ \\
\hline 2. & Klebsiella pneumoniae & 3 & $13.64 \%$ \\
\hline 3. & Proteus mirabilis & 3 & $13.64 \%$ \\
\hline 4. & Klebsiella oxytoca & 2 & $9.09 \%$ \\
\hline 5 & Citrobacter freundii & 2 & $9.09 \%$ \\
\hline 6 & Enterococcus faecalis & 2 & $9.09 \%$ \\
\hline 7. & Staphylococcus aureus & 1 & $4.55 \%$ \\
\hline \multicolumn{2}{|r|}{ Total } & $\mathbf{2 2}$ & $\mathbf{1 0 0 \%}$ \\
\hline & \multicolumn{2}{|r|}{ Table 1: Bacteriological isolates in urine samples } \\
\end{tabular}

Escherichia coli (40.90\%) was the most common isolate and followed by Klebsiella pneumoniae (13.64\%) and Proteus mirabilis (13.64\%). 


\begin{tabular}{|c|l|c|c|}
\hline Serial No & \multicolumn{1}{|c|}{ Method } & $\begin{array}{c}\text { Number of positive cases } \\
\text { (Total - 22) }\end{array}$ & Percentage \\
\hline 1. & Pyuria & 11 & $50 \%$ \\
\hline 2. & Catalase Test & 15 & $68.2 \%$ \\
\hline 3. & Nitrate Reduction Test & 12 & $54.5 \%$ \\
\hline 4 & Culture & 22 & $100 \%$ \\
\hline \multicolumn{3}{|c|}{ Table 2: Shows the accuracy of microscopy catalase test, } \\
nitrate reduction test and culture method. \\
\hline
\end{tabular}

Table 2 shows the accuracy of different method of screening i.e. Microscopy, catalase test, nitrate reduction test and culture. Culture shows highest rate of sensitivity and then was catalase test. The isolates were sensitive to amikacin (90\%). Cefotaxim (78\%) was the drug which showed sensitive to isolates and then was cefuroxime (65\%) nitrofurantoin (60), ampicillin (9\%) and amoxicillin (15\%).

DISCUSSION: The prevalence of asymptomatic bacteriuria has been documented to be as high as 30 to $50 \%$. [9] Within the asymptomatic pregnant women the prevalence of positive culture was $11.22 \%$ (22). The present study when compared with other studies shows the similar identified isolates. The prevalence rate vary from $4 \%$ to $23.9 \%$ in studies conducted by various authors.[10] The prevalence rate falls within this range. The prevalence of positive culture increased with the age.[11] Present study included $9.7 \%$ between the age group 15-25 years and $19.3 \%$ in between 26-40 years. Prevalence of positive cases increased with age. Most cases of asymptomatic bacteriuria were found

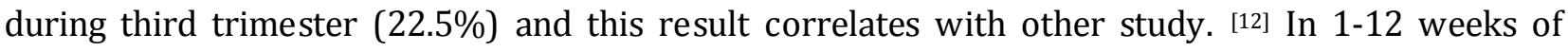
gestation 5 (16.6\%) were recorded and between $13-24$ weeks of gestation $11(8.1 \%)$ cases were recorded. Escherichia coli (40.90\%) was the common isolate and was correlated with other studies [1][4][13][14] This was followed by Klebsiella pneumoniae (13.64\%), Proteus mirabilis (13.64\%) Klebsiella oxytoca (99.09\%) Citrobacter freundii (9.09\%), Enterococcus faecalis (9.09\%) and Staphylococcus aureus (4.55\%). Catalase test (68.2\%) showed highest [11] accuracy than nitrate reduction test (54.5\%) and pyuria (50\%). Amikacin (90\%) was the drug which showed increased sensitivity. ${ }^{[14]}$ Then were cefotaxime (78\%), cefuroxime (65\%) and nitrofurantoin (60\%) Amoxicillin (15\%) and ampicillin (9\%) was found to be least sensitive.

CONCLUSION: The present study included the prevalence of asymptomatic bacteriuria. This includes age, gestational age and accuracy of screening to culture, the organism isolated and its sensitivity. Gram negative organisms were the commonest organism isolated and above all Escherichia coli was the main urinary pathogen isolated. Prevalence of bacteriuria increased with age of women. The isolates were mostly sensitive to amikacin followed by cefotaxine, cefuroxime, and nitrofurantoin.The isolated organisms were found least sensitive to ampicillin. Culture of urine was the most effective method of detection of asymptomatic bacteriuria during pregnancy.

\section{REFERENCE:}

1. Enayat K, Fariba F, Bahram N, Asymptomatic bacteriuria among pregnant women referred to outpatient clinics in Sanandaj, Iran. Int Braz J urol 2008; 34(6):699-707. 
2. Delzell JE, Lefevre ML. Urinary tract infections during pregnancy. Am Fam Physician. 2000; 61:713-21.

3. Jayalakshmi J, Jayaram VS. Evaluation of various screening tests to detect asymptomatic bacteriuria in pregnant women. Indian J Pathol Microbiol 2008; 51(3):379-381.

4. Kacmaz B, Cakir OI, Aksoy A, Biri A. Evaluation of rapid urine screening test to detect asymptomatic bacteriuria in pregnancy. Jpn J Infect Dis. 2006; 59(4):261-263.

5. Sheffield JS Cunningham FG. Urinary tract infection is women. Obstet Gynecol 2005; 106:10851092.

6. Stenquist K, Sandberg T, Lidin-Janson G et al. Virulence factors of Escherichia coli in urinary isolates from pregnant women. J Infect Dis 1987; 156:870-877.

7. Gayathree L, Shetty S, Desh pande SR, Venkatesh DT. Screening for asymptomatic bacteriuria in pregnancy: An evaluation of various screening tests in Hassan District Hospital, India. JCDR 2010; 4940:2702-2706.

8. Schieve LA, Handler A, Hershow R, Persky V, Davis F. Urinary tract infection during pregnancy, its association with maternal morbidity and perinatal outcome. Am J pub Health 1994; 84930:405-410.

9. Nicolle LE, Asymptomatic bacteriuria in the elderly. Infect Dis clin North Am 1997; 11:647662.

10. Lavanye SV, Jogalakshmi D. Asymptomatic bacteriuria in antenatal cases. Indian J Med Microbiol. 2002; 2(20): 105-106.

11. Ansari HQF, Rajkumari A Prevalence of asymptomatic bacteriuria and associated rest factors among antenatal women attending \& tertiary care hospital. J Med allied sciences 2011;1(2):7478.

12. Saeed S, Tariq P. Symptomatic and asymptomatic urinary tract infections during pregnancy. Intl J. Microbiol. Res 2011; 2(2):101-104.

13. Imade PE, Izekor PE, Eghafone NO, Enabulele OI, Ophori E, Asymptomatic bacteriuria among pregnant women. North Am J med Sci 2010; 2(6):263-266.

14. Girishbabu RJ, Srikrishna R, Ramesh ST. Asymptomatic bacteriuria in pregnancy. International Journal of Biological \& Medical Research 2011; 2(3):740-742.

\section{AUTHORS:}

1. Babita

2. Sanjeev Suman

3. Shankar Prakash

\section{PARTICULARS OF CONTRIBUTORS:}

1. Tutor, Department of Microbiology, Patna Medical College Hospital.

2. Senior Resident, Department of Microbiology, Patna Medical College Hospital.

3. H.O.D., Department of Microbiology, Patna Medical College Hospital.

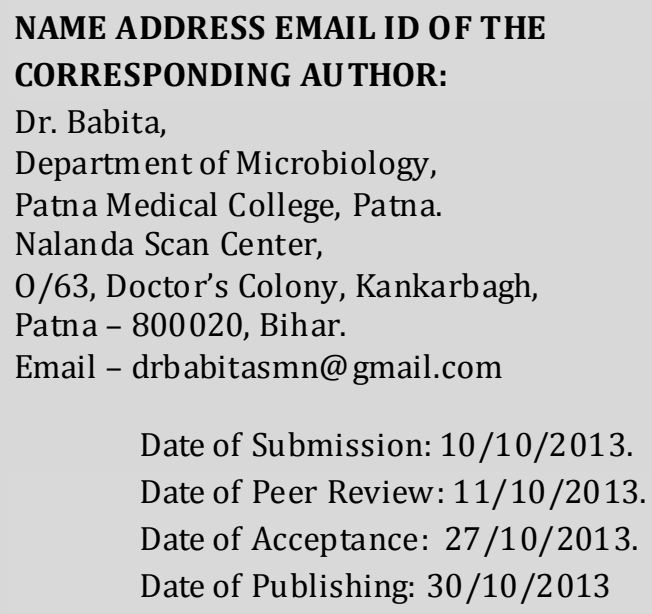

NAME ADDRESS EMAIL ID OF THE CORRESPONDING AUTHOR:

Dr. Babita,

Departm ent of Microbiology,

Patna Medical College, Patna.

Nalanda Scan Center,

0/63, Doctor's Colony, Kankarbagh,

Patna - 800020, Bihar.

Email - drbabitasmn@gmail.com

Date of Submission: 10/10/2013.

Date of Peer Review: 11/10/2013.

Date of Acceptance: 27/10/2013.

Date of Publishing: 30/10/2013 